\title{
GEOSPATIAL SERVICE AND APPLICATION BASED ON NATIONAL E-GOVERNMENT NETWORK PLATFORM AND CLOUD
}

\author{
Meng xianghui ${ }^{\mathrm{a}}{ }^{\text {deng yuanyuan }}{ }^{\mathrm{b}}$, li haochuan ${ }^{\mathrm{c}}$, yao $\mathrm{lu}^{\mathrm{c}}$, shi jian ${ }^{\mathrm{c}}$ \\ a The fifty-fourth Research Institute of China Electronic Technology Group Corporation, \\ Shijiazhuang Zhongshan West Road No. 491,china, mxh1983228@163.com \\ ${ }^{\mathrm{b}}$ National Marine Data and Information Service, Tianjin City West Road No. 219 Nankai District mustard by No. 1,ch, \\ china, tang1yuan@163.com \\ c The State Information Center, The Three River Road Beijing City, No. 58 Xicheng District, china, \\ (lihc,shij,yaol)@mx.cei.gov.cn
}

\section{Commission}

KEY WORDS: national e-government, cloud, geo-spatial information resources, data integration, cross-sectoral, standardization, product, service

\begin{abstract}
:
With the acceleration of China's informatization process, our party and government take a substantive stride in advancing development and application of digital technology, which promotes the evolution of e-government and its informatization. Meanwhile, as a service mode based on innovative resources, cloud computing may connect huge pools together to provide a variety of IT services, and has become one relatively mature technical pattern with further studies and massive practical applications. Based on cloud computing technology and national e-government network platform, "National Natural Resources and Geospatial Database (NRGD)" project integrated and transformed natural resources and geospatial information dispersed in various sectors and regions, established logically unified and physically dispersed fundamental database and developed national integrated information database system supporting main e-government applications. Cross-sector e-government applications and services are realized to provide long-term, stable and standardized natural resources and geospatial fundamental information products and services for national egovernment and public users.
\end{abstract}

\section{RELATIONSHIP BETWEEN E-GOVERNMENT AND GEOGRAPHIC INFORMATION APPLICATION}

Geographic information is the spatial orientation basis and vector of e-government information resources, and its application contributes to integrating government information and promoting public service, which lays a solid foundation for motivating cross-sector e-government as well as collaborative service of other departments and information systems. Taking geographic information system (GIS) as the application subject, realizing cross-sector application integration and data transformation and improving standardization and information sharing have become an important pattern in current egovernment construction, whose popularization will largely solve disunity of e-government information standard and low sharing level situation. Various departments are required to submit their own authoritative data and exhibit informatization achievements via unified geographic information platform, not only to meet business management needs, but also to arouse the enthusiasm of each department to take part in project construction and operation in favor of forming benign multisector and multi-system collaborative service prospect. Geographic information application significantly advances technological progress of government administration offices. Meanwhile, e-government also promotes geographic information resources construction and technological progress, and accordingly boosts geographic information technology development.

\section{TREND OF OVERSEA E-GOVERNMENT GEOSPATIAL SERVICE AND APPLICATION}

To increase government work efficiency, e-government attracts more and more attention of national governments, among which America is one of those early putting into effect e-government strategy and has acquired remarkable accomplishments through years of growth. Moreover, America is the forerunner of GIS development and application, and American government is the supreme GIS user in the world as far as its system quantity and data volume are concerned. GIS software researchers and hardware manufacturers in America occupy absolute proportion and have expanded into an independent and integrated industry .American E-government spatial service and application represent world banner level and have the following characteristics.

\section{Attached by Government}

Led by America Presidential Management Committee, and jointly implemented by Executive Office of the president and Office of Management and Budget, American government has built forceful leading agencies on e-government development and construction, which actualized unified and coordinated leadership nationwide.

American government made tremendous contribution to GIS development, application and popularization with over One 
hundred million dollars on GIS research and application annually. Despite America faced serious economic recession and defense expenditure was substantially cut down in recent years, investment in GIS and relevant technology conversely increased 3\% with corresponding development planning marked out .Federal agency, as the primary source and issuer of remote sensing images, has turned into the bellwether in GIS database development and data standard setting . Meanwhile, state governments and local agencies intently cooperated to carry out data acquisition, issuance and digital precision standard revision.

\section{Extensive Service}

America is one of the most extensive and popular countries in applying information technology in the world today. Information technology has brought earthshaking historical changes in government administration, enterprise operation and daily life of common people. In the development history of American e-government, GIS development and application hold a highly important position. The combination of GIS technology and geographic information dataset proves to be the major tool of analyzing, processing and displaying various information resources, and is being widely applied in many fields from homeland security, government affairs to civilian daily life, such as city planning, environmental service, traffic service, safety service, administrative management, regular service, etc. Over half government departments directly utilize GIS to improve working mode and augment work efficiency.

\section{Advanced Technology}

Web decision-making supportive system has been established for decision analysis through adopting leading-edge cloud computing technology, e-government geographic information service concept based on service-oriented architecture (SOA) and loose coupling structure of software function. Thus the security and service mode are more reliable based on centralized network information platform of American government departments.

\section{STATUSOF DOMESTICE-GOVERNMENT GEOSPATIAL SERVICE AND APPLICATION}

China started embarking on e-government construction from the end of 1990.According to “ Guidance of National Informatization Leading Group on E-government Construction in China " forwarded by General Office of the CPC Central Committee and General Office of the State Council in 2002, the first meeting of national informatization leading group determined to take e-government construction as our informatization work focus in the next period, further accelerate building government platform, integrate information resources and unify standards. Informatization work mainly focus on " Two networks, one website, four databases and twelve golden projects " based on the principle of government first to stimulate national economy growth and information society development. As a state-level information database, NRGD project among the four databases national emphasis on geographic information resources construction and vital role of geographic information resources in national e-government.

After years of hard work, China has completed e-government network construction, launched e-government oriented geographic information technology service and advanced egovernment geographic information platform construction. A batch of synthetical geographic information systems, thematic business systems and various service systems for government application have been established to improve government comprehensive management and decision-making level and important strategy implementation. However, there is still a big gap in e-government geospatial service compared with developed countries abroad, which is mainly embodied as follows.

1. Shortage of geographic information resources. Our GIS construction started relatively late and technical strength is weak. Data offered are unable to meet application needs due to problems in slow updating, lag in measure, low accuracy and poor quality.

2. Geographic information standardization needs to be further strengthened. Classification of our geographic information standards is complicated and various in type, thus unified standard system greatly need to be built.

3. Geographic information resources dispersion and data format disunity. At present our geographic information resources scatter in diverse divisions such as surveying and mapping, water resources, communications, civil affairs, etc. and come into data islands because of data isolation and format disunity.

4. Difficulty in geographic information sharing. Imperfect geographic information sharing mechanism brings about a great deal of information achievement incapable of intercommunication and sharing as well as duplicate information acquisition, which goes against the full use of information resources and elimination of data islands.

5. Poor geographic information service ability. Egovernment application software is not compactly combined with business requirements. In addition, type and quantity of geographic information products adapting to information age are insufficient, and distribution pattern is excessively single. Thus application service function based on network should be further improved.

\section{GEOSPATIAL SERVICE AND APPLICATION BASED ON NATIONAL E-GOVERNMENT NETWORK PLATFORM AND CLOUD IN NRGD}

\subsection{Project background}

According to the needs of national e-government development, NRGD project is constructed under the leadership of the State Development and Reform Commission, participated in jointly by 11 departments, including Ministry of Land and Resources, Ministry of Water Resources, Chinese Academy of Sciences, State Oceanic Administration, State Bureau of Surveying and Mapping, State Forestry Administration, China Meteorological Administration, China Aerospace Science and Technology Corporation, etc..As one of the four basic information databases determined by document No.[2002]17 of General Office of the CPC Central Committee and launched the first, NRGD is the core project of National Spatial Information Infrastructure ,belonging to system engineering project which geographic information science and spatial technology are integrated into.

Relying on existing informatization infrastructure, NRGD project integrates and transforms information resources now available in the light of unified criterion, builds fundamental 
natural resource thematic database, fundamental geospatial thematic database, natural resource and geospatial synthetical database and geospatial information exchange system. 1 primary datacenter and11 branch datacenters of NRGD are formed to enhance macro supervision, dynamic monitoring and predictive ability for regional development and resource environment, and further improve information sharing to render service for the public.

NRGD is the largest, civil-military integrated, cross-sector and strongly comprehensive geospatial data sharing project since the founding of new China. Both the project organization and technology system give full play to multi-sector joint construction mechanism. Eventually the logically unified and physically dispersed fundamental database is established based on e-government extranet with cloud computing technology.

\subsection{Application service mode}

\subsubsection{Logically unified and physically dispersed data storage} and access pattern based on e-government extranet

\section{Business analysis}

NRGD integrates massive information resource scattered in various sectors under the national e-government overall framework, to create useful information products. The multisector data storage and access are realized through the service interface of NRGD exchange system in accordance to international standards, to access data resource of primary datacenter and branch datacenters. Through the function of sharing and exchanging service of various standards, to meet the requirements of NRGD participating departments and other governmental departments that have access to e-government network. Through multiple forms of service access, incorporation of natural resources of NRGD into respective business application systems realizes extensive data resource sharing.

The system provides unified application interface to users, to realize single-site spatial information network sharing and application service. Based on the metadata and spatial data sharing platform, spatial metadata sharing service system achieves metadata network management and publishing of primary datacenter and branch datacenters, to realize the functions of distributed management, unified publishing, catalog service, etc. Based on the spatial metadata sharing service system, spatial data virtual database system, and spatial data sharing service system, spatial information application service system integrates functions of metadata query service, data sharing service, etc., to provide unified application interface to users.

\section{Technology realization}

Exchange system realizes integration function of spatial information application service with SOA architecture and provides bran-new design norm for cross-sector, cross-regional and cross-industrial nationwide information sharing and exchange network service among government departments. It offers support for aggregation of synthetical information subdatabase, data exchange for synthetical information database, synthetical product database, synthetical custom product database, thematic information database, and thematic product database, as well as data supporting environment for various application systems. National geospatial information resource sharing and exchange hub is formed to render sharing service to users with multilayer unified software technology architecture including data layer, platform layer, service layer, application layer and user layer.

(1) Data layer contains synthetical information database, synthetical product database, thematic information database, thematic product database, provincial pilot information database, metadata and core metadata database, etc., realized with Oracle11g, DB2 database system.

(2) Platform layer contains GIS middleware, application middleware, metadata server, metadata gateway , among which GIS middleware includes ARCGIS Server, ARCSDE , etc., application middleware includes J2EE application server, database middleware and portal server.

(3) Service layer contains WMS, WFS, WCS, information order Service, data download service and catalog service, etc., among which WMS, WFS and WCS are provided by spatial data sharing service system, information order Service, data download service and catalog service are realized with Web Service technology.

(4) Application layer contains metadata query and portal web. Metadata query integrates data preview and data download application. Portal web integrates metadata query, information product web application and information order service.

(5) User layer contains browser users and system users. Browser users visit portal website via browser, while system users may directly access catalog service.

\subsubsection{Distributed multi-sector collaborative and custom}

\section{production pattern based on cloud}

\section{Business analysis}

Original business analysis system functions are unable to adjust as needed owing to system hugeness, functional complexity and business analysis module solidification. Facing characteristics of target diversification, demand changefulness and response rapidness in government decision-making sections, business analyst know what to want ,but don't know how to do. Government department and industry possess massive professional data, few of which are turned into information resources with social service ability, resulting that the development of economic society urgently need data on one hand, and useful information lie idle in data owners on the other hand. Part scientific research institution shave solid theory foundation, strong technical strength and professional product processing personnel, yet deficiency of information resources restricts promotion of domestic research level. NRGD combined need, data and process with e-government network platform, and adopted cloud computing technology .to realize longitudinal multi layers, horizontal grid custom application integration platform architecture, whose application mode is shown in figure 1. Application integration platform carried out cross-set oral information processing, model synthetic analysis and custom production as in figure 2 . 


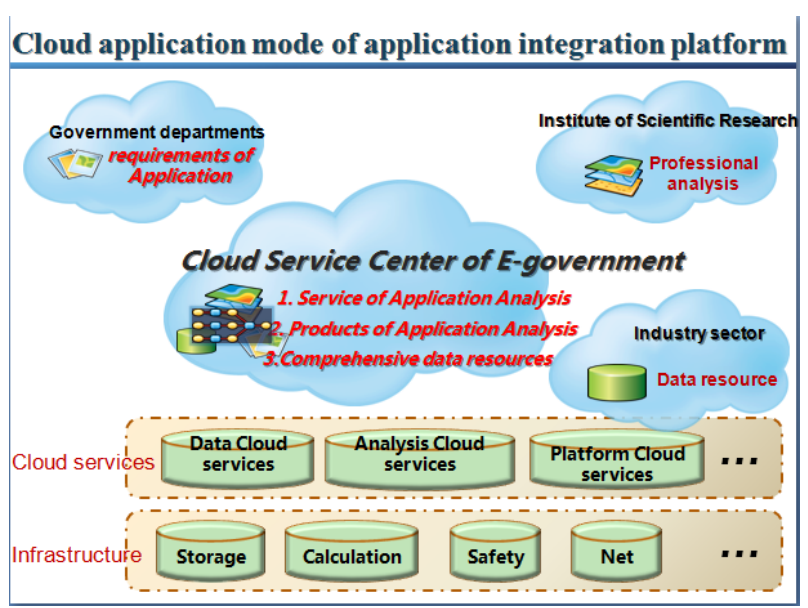

figure 1. Cloud application mode of application integration platform

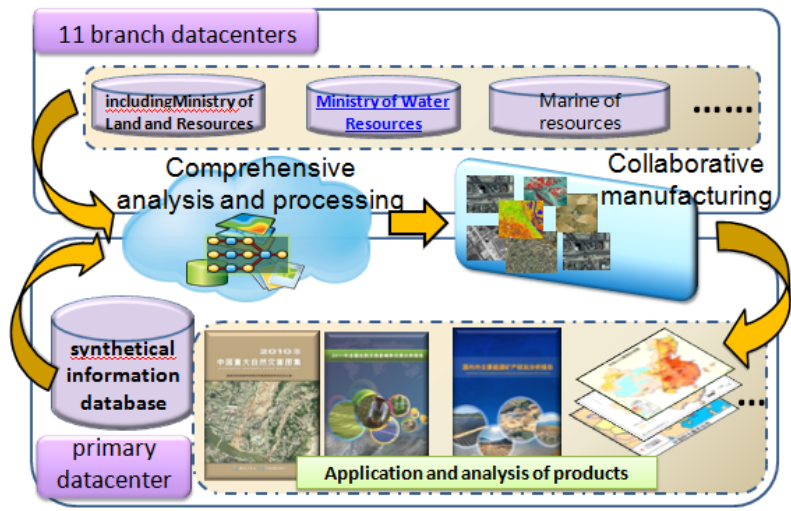

figure 2. multi-sector collaborative analyzed synthetical custom product developing mode

\section{Technology realization}

Based on SOA architecture, custom application integration platform was established including model base and application building system based on workflow. With functions provided by this platform, information resources of NRGD and other than NRGD can be used to conduct information product processing, production, and distribution and application system development, to better play the role of NRGD and offer diverse and highly specialized information service for government sector at different levels and the public.

(1) Model library integrated a group of basic components, universal components, application components to meet application models in 6 application directions: comprehensive monitoring of resource, comprehensive evaluation of ecological environment and sustainable development, monitoring of major natural disasters and post-disaster reconstruction planning, regional planning and major function zones planning, tracking and benefit evaluation of resource environment planning and major infrastructure project, monitoring and assessment of marine resources exploitation and economy development. According to criterion of application integration platform, models that meet new demand can also be developed with different development languages to expand model library constantly. Models follow the ability of building principle, which means each model is like one small building block, and small building blocks construct big building block which can be put in application to execute.

(2) Application building system based on workflow provides various granular model visualized building, realizes on-demand, immediately and flexibly adjusting model stream. Plug-in, building and configured redevelopment is supported to abolish repeat work and redundant resources and optimize development process. Building and configuration technology instead of traditional manual encoding realize scale production of software development and tremendously increase efficiency of system development. Besides, application system developed is capable of possessing both C/S and $\mathrm{B} / \mathrm{S}$ framework through one design.

3. Heterogeneous model library management technology. Standard plug in model interface and universal component interface are offered to incorporate functions of other application systems after which are normalized encapsulation into plug in library and component library to complete function integration. Based on the interfaces users can develop functions full of characteristics of their own field and embed these functions into system in automatic or manual register way, to enable model function expansion for easy to use and avoid island formation of entire system on functional level. A large number heterogeneous models both in different types and sources are supported, as well as mainstream GIS software home and abroad such as MapGIS model, ArcGIS model, Supper MAP model and other re-development models.

(3) Multisource and heterogeneous spatial data management technology. By means of defining standard interface of GIS middleware, to realize data management mechanism using middleware technology, which overcome data use disorder because of heterogeneity and distribution to retain that advantage and meanwhile provide consistent service interface and mode for more users of resource sharing, coordinate processing and task cooperating. As internal data reading interface is regulated by application integration platform, multi-format data direct access, data integration independent of format and location, composite analysis and seamless integration of multisource and heterogeneous data are achieved through processing data from different sources with corresponding drivers.

(4) Building and configuration technology. Application systems built with integration platform are capable of breaking through business system oriented specific business system development and problem oriented traditional development mode. Taking configured and built re-development as major developing mode, accompanied by few coded plug in re-development, can rapidly build diversified application systems in GIS field.

\section{CONCLUSION}

With the acceleration of China's informatization process, our party and government take a substantive stride in advancing development and application of digital technology, which promotes the evolution of e-government and its informatizaiton. Relative to e-government development, geographic information technology lags comparatively and traditional system developing and running mode on longer meet rapid development needs of information technology nowadays. Introducing distributed memory, management and service mode of cloud computing technology into geographic information 
technology and applying them extensively certainly will bring about new innovation in geographic information technology area and promote geographic information technology development.

\section{References from Journals:}

Z. D. Chen, D. Q. Chen, "Consideration of some problems in geographic information application in e-government," egovernment standard, 2006. 12(6). pp. 39-43

Y. Q. Chang, "Status and future development of geographic information service in e-government,” Science of Surveying and Mapping, 2006.Vol31.No2.

H. Wu, B. W. Sun, "Status, problem and counter measure empirical research of e-government development nowadays in China, "Journal of China National School of Administration, 2009.05. pp.123-128

G. Y. Gong, "application status and reference of American city geographic information system construction, ”Journal of Chengdu Administration Institute, 2009.04

Z. C. Wang, "Application and technology development status of American geographic information system, "Management of Forest Resources, 1996.

G. P. Liu, "SOA-based e-government geospatial information service and realization, "Journal of Liaoning Technical University, 2006.Vol25

\section{References from Other Literature:}

National informatization leading group, "Guidance on egovernment construction in China," 2002.

Revised March 2012 